\title{
Simultaneous Optimization of Network Reconfiguration and DG Installation Using Heuristic Algorithms
}

\author{
Ahmet Dogan, Mustafa Alci \\ Department of Electrical \& Electronics Engineering, Faculty of Engineering, Erciyes University, \\ 38039, Kayseri, Turkey \\ ahmetdogan@erciyes.edu.tr
}

\begin{abstract}
Network reconfiguration and distributed generation (DG) installation are important approaches for loss mitigation and system efficiency improvement. To date, these approaches are generally implemented separately. In this work, simultaneous network reconfigurations and DG installation is solved in order to minimize real power loss and improve system efficiency using popular heuristic algorithms such as Artificial Bee Colony (ABC), Differential Evaluation (DE), Particle Swarm Optimization (PSO) and Genetic Algorithm (GA). While decision making is carried out for open switches and DG sizing by given algorithms, optimal locations of DGs are decided using loss sensitivity factor in order to reduce searching space. Different cases of network reconfiguration and DG installation are implemented to compare the performances of given heuristic algorithms. Branch current, bus voltages and DG capacity are considered as constraints and 69 bus system is used for simulation. This study demonstrates that simultaneous network reconfiguration and DG installation presents better solutions than any other cases and ABC has proven minimum losses and maximum voltage improvement.
\end{abstract}

Index Terms-Heuristic optimization; Network reconfiguration; Distributed generation; Distribution system.

\section{INTRODUCTION}

Power losses mostly occur in transmission and distribution (T\&D) lines in an electrical network. These losses affect operation of a system negatively and they lead to financial losses. Hence, minimization of T\&D losses in the most efficient way is an important issue. Network reconfiguration and distributed generation (DG) allocation are proposed approaches for loss minimization and system improvement. So far, network reconfiguration and distributed generation are generally discussed separately. In this work, however, network reconfiguration and DG installation are solved simultaneously to mitigate losses and improve voltage profile.

Network reconfiguration is defined as changing topology of a distribution system using open/close position of the sectional and tie switches [1]. There has been a lot of work related to the reduction of losses using network reconfiguration in the literature. In [2], heuristic algorithms which decide the statuses of switches are proposed and simple formula are used to calculate power loss calculation.

Manuscript received 17 May, 2018; accepted 4 November, 2018.
However, authors consider only one switching operation. Also, artificial intelligence and modern heuristics algorithms are used for solution of network reconfiguration problem [3]-[5], [6]-[8]. Recently, Fireworks Algorithm [9] and twostage robust optimization models [10] are proposed to optimize economic benefits. Although network reconfiguration reduces losses, it may not be sufficient to meet the increasing demand.

DGs are located in distribution network to meet power demand, increase voltage level, mitigate losses and benefit financially. In order to benefit from the DGs optimally, they must be installed at proper sizes and proper locations. In [11], loss sensitivity factor and GA are used for DG location and size, respectively. In [12], DG installation is optimized in order to increase voltage level considering load demand and renewable sources. In [13], a method is suggested to calculate place and size of multiple DG. In [14], PSO is proposed for DG installation to decrease power losses. In [15], various methods are compared for optimal location of DG. In [16], multi-objective optimization is carried out for economic analysis of DG owner's and distribution company's point of view considering system requirements.

There are some works in literature about simultaneous optimization of network reconfiguration and DG installation. In [17] and [18], hyper cube-ant colony optimization and modified plant growth simulation algorithm are applied only for small scale 33 bus system. In [19], Evolutionary programming and Genetic Algorithm are compared for 33bus test system. In [1], harmony search algorithm (HSA) is carried out for 33 bus and 69 bus system and results are compared with genetic algorithm and refined genetic algorithm (RGA) which already exist in the literature.

This paper contributes that 69 bus system which is relatively larger is used to be optimized. Loss sensitivity factor is calculated to reduce searching space. ABC, DE, PSO and GA are carried out for four cases and results are compared for each case. Furthermore, works in the literature are included in the comparison. Mathematical formulation of problem is given in Section II, loss sensitivity factor is explained in Section III, heuristic methods are presented in Section IV, simulation results are presented in Section V, results are discussed in Section VI and conclusion is located in Section VII. 


\section{PROBLEM IDENTIFICATION}

\section{A. Power Flow Formulations}

Single line illustration of distribution feeder is given in Fig. 1 and power flows between distribution feeders are calculated using (1), (2) and (3) [1], [20].

Sending End

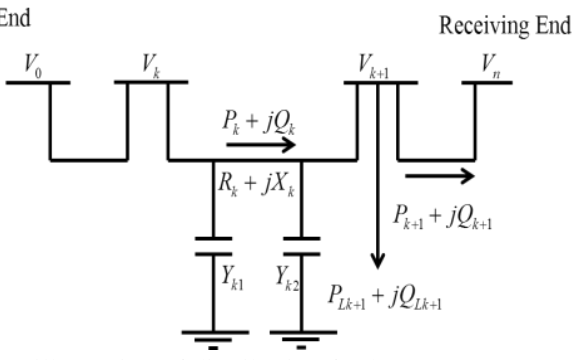

Fig. 1. Single line illustration of distribution feeder [1].

$V_{k}$ is voltage magnitude at bus $k . P_{k}, Q_{k}, R_{k}$ and $X_{k}$ are active power flow, reactive power flow, resistance and reactance between bus $k$ and $k+1$, respectively. $P_{L k+1}$ and $Q_{L k+1}$ are active and reactive load at $k+1 . Y$ is shunt conductance which indicates leakage current between conductance. $Y$ is considered zero in calculations due to capacitance of distribution lines are extremely small:

$$
\begin{gathered}
P_{k+1}=P_{k}-P_{\text {Loss }, k}-P_{L k+1}= \\
=P_{k}-\frac{R_{k}}{\left|V_{k}\right|^{2}}\left\{P_{k}^{2}+\left(Q_{k}+Y_{k}\left|V_{k}\right|^{2}\right)^{2}\right\}-P_{L k+1}, \\
Q_{k+1}=Q_{k}-Q_{\text {Loss }, k}-Q_{L k+1}= \\
=Q_{k}-\frac{X_{k}}{\left|V_{k}\right|^{2}}\left\{P_{k}^{2}+\left(Q_{k}+Y_{k 1}\left|V_{k}\right|^{2}\right)^{2}\right\}- \\
-Y_{k 1}\left|V_{k}\right|^{2}-Y_{k 2}\left|V_{k+1}\right|^{2}-Q_{L k+1}, \\
\left|V_{k+1}\right|^{2}=\left|V_{k}\right|^{2}+\frac{R_{k}^{2}+X_{k}^{2}}{\left|V_{k}\right|^{2}}\left(P_{k}^{2}+\left(Q_{k}+Y_{k}\left|V_{k}\right|^{2}\right)^{2}\right)- \\
-2\left(R_{k} P_{k}+X_{k}\left(Q_{k}+Y_{k}\left|V_{k}\right|^{2}\right)\right) .
\end{gathered}
$$

The power losses between buses are computed using (4) and total power loss in a distribution system is computed using (5):

$$
\begin{gathered}
P_{\text {Loss }}(k, k+1)=R_{k} \frac{\left(P_{k}^{2}+\left(Q_{k}+Y_{k}\left|V_{k}\right|^{2}\right)^{2}\right)}{\left|V_{k}\right|^{2}}, \\
P_{T, \text { Loss }}=\sum_{k=1}^{n} P_{\text {Loss }}(k, k+1) .
\end{gathered}
$$

\section{B. Loss Mitigation after Network Reconfiguration}

The power loss between buses and total loss after reconfiguration are defined by (6) and (7), respectively:

$$
P_{\text {Loss }}^{\prime}(k, k+1)=R_{k} \frac{\left(P_{k}^{\prime 2}+\left(Q_{k}+Y_{k}\left|V_{k}\right|^{2}\right)^{\prime 2}\right)}{\left|V_{k}^{\prime}\right|^{2}},
$$

$$
P_{T, \text { Loss }}^{\prime}=\sum_{k=1}^{n} P_{\text {Loss }}^{\prime}(k, k+1)
$$

Active power loss mitigation after reconfiguration is formulated as follows

$$
\Delta P_{\text {Loss }}^{R}=\sum_{k=1}^{n} P_{T, \text { Loss }}(k, k+1)-\sum_{k=1}^{n} P_{T, \text { Loss }}^{\prime}(k, k+1) .
$$

\section{Loss Mitigation after DG Installation}

DG installation into distribution systems has been increasing due to liberalization of electricity markets, environmental concerns and high cost of transmission line buildings. The benefits of DG are mitigation of power losses, voltage profile and network reliability improvement, deferred network expansion cost, reduced environmental impacts etc. Power loss after DG penetration is given by (9) [1]

$$
\begin{gathered}
P_{D G, \text { Loss }}=\frac{R_{k}}{V_{k}^{2}}\left(P_{k}^{2}+\left(Q_{k}+Y_{k}\left|V_{k}\right|^{2}\right)^{2}\right)+ \\
+\frac{R_{k}}{V_{k}^{2}}\left(P_{G}^{2}+Q_{G}^{2}-2 P_{k} P_{G}-2\left(Q_{k}+Y_{k}\left|V_{k}\right|^{2}\right) Q_{G}\right)\left(\frac{G}{L}\right) .
\end{gathered}
$$

Active power loss mitigation $\Delta P_{\text {Loss }}^{D G}$, after DG penetration is given by (10)

$$
\begin{gathered}
\Delta P_{\text {Loss }}^{D G}=\frac{R_{k}}{V_{k}^{2}} \times \\
\times\left(P_{G}^{2}+Q_{G}^{2}-2 P_{k} P_{G}-2\left(Q_{k}+Y_{k}\left|V_{k}\right|^{2}\right) Q_{G}\right)\left(\frac{G}{L}\right),
\end{gathered}
$$

where $G$ is length of feeder from source to bus and $L$ is distance from source to DG. However, $(G / L)$ is ignored in calculations.

\section{Objective Function}

Objective function aims to maximize active power losses mitigation after simultaneous network reconfiguration and DG installation as follows

$$
\begin{gathered}
f=\max \left(\Delta P_{\text {Loss }}^{R}\right)+\max \left(\Delta P_{\text {Loss }}^{D G}\right), \\
\text { Subject to }\left\{\begin{array}{l}
V_{\text {min }} \leq V_{k} \leq V_{\text {max }}, \\
\sum_{k=1}^{n} P_{G k} \leq \sum_{k=1}^{n}\left(P_{k}+P_{\text {Loss }, k}\right), \\
\left|I_{k, k+1}\right| \leq\left|I_{k, k+1, \max }\right| .
\end{array}\right.
\end{gathered}
$$

\section{CAlCUlation of Loss SENSITIVITY FACTOR}

Loss sensitivity factor of each bus is calculated to determine buses for DG installation. Buses are sorted taking into account their effect for optimum solution of system and the buses with highest priority is selected for DG installation. Thus, searching space of optimization procedure is reduced. Active power loss between $k-1$ and $k$ can be 
calculated as follows

$$
P_{\text {lineloss }}=\frac{\left(P_{L k, \text { eff }}^{2}+Q_{L k, \text { eff }}^{2}\right) R_{k}}{V_{k}^{2}},
$$

where $P_{L k, \text { eff }}+Q_{L k, e f f}, V_{k}$ and $R_{k}$ are effective power, voltage and resistance of $k$ th bus. The effective power consists of output power and power consumed in actuating auxiliary units or mechanisms that are necessary for the engine's operation. Effective power is considered for loss calculations and $Y$ is ignored due to explanation previous section. Loss sensitivity factor of $k$ th bus is defined as follows

$$
\frac{\partial P_{\text {lineloss }}}{\partial P_{L k, e f f}}=\frac{2 \times P_{L k, e f f} \times R_{k}}{V_{k}^{2}} .
$$

\section{HEURISTIC AlgORITHMS}

In this work, DG placement and network reconfiguration problems are solved together. Loss sensitivity factor is used for DG placement in order to reduce searching space as explained in Section III. Optimal reconfiguration is described with position of open switches. Number of tie switches $n$, corresponds to length of reconfiguration problem which is first component of solution vector. Similarly, number of installed DG $m$, is the length of second component of solution vector as follows

$$
x=[\underbrace{S_{1}, S_{2}, \ldots, S_{n}}_{\text {reconfiguration }}, \underbrace{P_{D G 1}, P_{D G 2}, \ldots, P_{D G m}}_{D G \text { sizes }}] .
$$

In order to maximize power loss reduction, DG sizes and sectionalizing switches are taken into account as control variables which are determined by ABC, GA, DE and PSO. Each of given algorithms initialize randomly and solution is improved with characteristic operators of each algorithms. Finally, best solution is selected considering their fitness values [21].

\section{A. Genetic Algorithm}

GA initialize with random solution set named population [22]. Population consists of chromosomes which represent possible solutions and composed of genes. Each gene indicates each variable. Hence, gene number equal to number of variables in a problem. GA mainly involves crossover, mutation and selection as operators. The crossover process synthesis the parents to reproduction. Mutation randomly exchanges the genes to explore search space. Selection operator decides fitness value of solution to transfer next generation.

\section{B. Differential Evaluation}

New individuals are produced with mutation, cross over and selection operators [23]. In mutation, donor vector $\left(v_{i, j}(t)\right)$ is produced using scaling factor $(F)$ and three chromosomes as follows

$$
v_{i, j}(t+1)=x_{r 1, j}(t)+F\left(x_{r 2, j}(t)-x_{r 3, j}(t)\right) .
$$

In cross over, current vector $X_{i}(t)$ and donor vector $V_{i}(t)$ are mixed with Crossover Rate $(C R)$ and trial vector $U_{i}(t)$ is produced as follows

$$
u_{i, j}(t)=\left\{\begin{array}{lc}
v_{i, j}(t), \text { if } & \text { rand }[0,1] \leq C R j=j_{\text {rand }} \\
x_{i, j}(t), & \text { otherwise }
\end{array}\right.
$$

In selection, the most fitted chromosome is sent to the next generation as follows

$$
X_{i}(t+1)=\left\{\begin{array}{lc}
U_{i}(t), & \text { if } f\left(U_{i}(t)\right) \leq f\left(X_{i}(t)\right), \\
X_{i}(t), & \text { otherwise. }
\end{array}\right.
$$

\section{Particle Swarm Optimization}

PSO is inspired by food search of particles in two dimensional spaces [24]. It works based on particle velocity and updating its position. Velocity variation of each particle is formulated as given

$$
\begin{aligned}
v_{t}^{(t+1)}= & w v_{i}^{(t+1)}+c_{1} r_{1}\left(\text { pbest }_{i}-x_{i}^{(t)}\right)+ \\
& +c_{1} r_{1}\left(\text { gbest }-x_{i}^{(t)}\right),
\end{aligned}
$$

where pbest is best previous solution, and gbest indicates best solution in global. $c 1, c 2$ are acceleration constants of pbest $_{i}$ and gbest $_{i} . r 1, r 2$ are selected between $[0,1], w$ is inertia weight factor, $t$ is generation number.

$$
x_{i}^{t+1}=x_{i}^{t}+v_{i}^{t+1} .
$$

\section{Artificial Bee Colony}

$\mathrm{ABC}$ is food search simulation of bee swarm [25]. ABC comprises onlooker, employed and scout bees. Scout bees search for new sources randomly, employed bees have a food sources and onlooker bees wait for finding new sources regarding food source quality of employed bees. In order to find new sources, $\mathrm{ABC}$ uses

$$
v_{i, j}=x_{i, j}+\phi_{i, j}\left(x_{i, j}-x_{k, j}\right),
$$

where $v_{i}$ represents new food source. More quality sources (best fitness) are selected by onlooker bees [26].

\section{Simulation Results}

69 bus test system is considered in order to compare the effectiveness of given heuristic algorithms for solving simultaneous network reconfiguration and DG installation. The distribution network is demonstrated in Fig. 2 [27]. System data are presented in [28]. Three DGs which are operated with a power factor of unity is considered and they cannot be connected to same bus. DGs are connected to any bus based on loss sensitivity factor and maximum capacity of DG is $2 \mathrm{MW}$ [18]. System voltage limits are 1.05 p.u. and 0.95 p.u. 


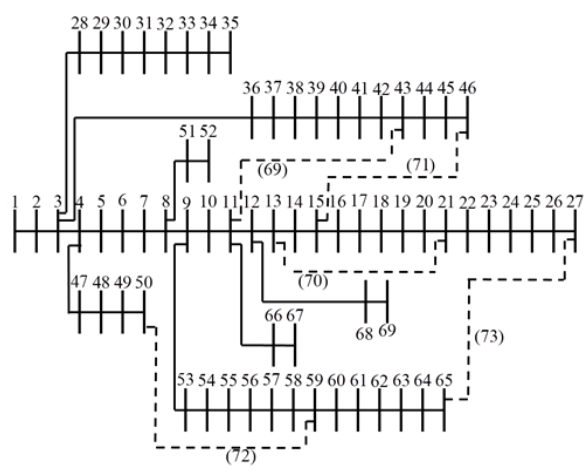

Fig. 2. 69-bus distribution network.

In the simulation of network, five cases are considered to compare the given algorithms.

Case- I : Base case;

Case- II: Only network reconfiguration;

Case-III: Only DG installation;

Case-IV: DG installation after reconfiguration;

Case-V: Simultaneous network reconfiguration and DG installation.

Common parameters; iteration number and population size are same for each algorithm. They are chosen to provide stabilization of algorithms convergence curves in a reasonable time. Simulations are carried out with different parameter values of heuristic algorithms and the parameters which give the best results are selected for simulations. The common parameters are the same as in [29]. Simulations are run for 25 times with selected parameters and best results among 25 simulations are presented. Iteration number and population size of given algorithms are 100 and 20, respectively. Selection type of GA is roulette. $C R$ and $F$ are selected 0.4 and 0.6 in DE. $c 1, c 2$ and $w$ are selected 1.2, 1.5 and 0.5 in PSO. Limit parameter of ABC is 100 .

In Case-I (base case), tie switches $(69,70,71,72,73)$ are normally open. Total real power loss is $224.98 \mathrm{~kW}$ and minimum bus voltage is 0.909 p.u. as given in Table I. Table II presents size and bus number of installed DG and opened switches by algorithms. Also, comparison of given heuristic algorithms is given with regarding voltage improvement and loss reduction for Case II-III-IV-V. Loss reduction indicates the loss differences between base case and simulated case. In Case-II, almost same reconfiguration topology of system is found by algorithms. Only ABC selected 58th switch differently instead of 55th switch to open among the simulated algorithms. However, results are same for each algorithm. Power loss, power loss reduction and minimum voltage level are $98.59 \mathrm{~kW}, 126.39 \mathrm{~kW}$ and 0.949 p.u. respectively.

TABLE I. 69 BUS SYSTEM POWER FLOW RESULTS FOR CASE-I

\begin{tabular}{|c|c|c|}
\hline Case & Item & Results \\
\hline \multirow{2}{*}{$\begin{array}{c}\text { Base Case } \\
\text { (Case-I) }\end{array}$} & Opened Switches & {$[69,70,71,72,73]$} \\
\cline { 2 - 3 } & Power Loss (kW) & 224.98 \\
\cline { 2 - 3 } & Min. Voltage Level (p.u.) & 0.909 \\
\hline
\end{tabular}

TABLE II. COMPARISON OF SIMULATION RESULTS OF HEURISTIC ALGORITHMS.

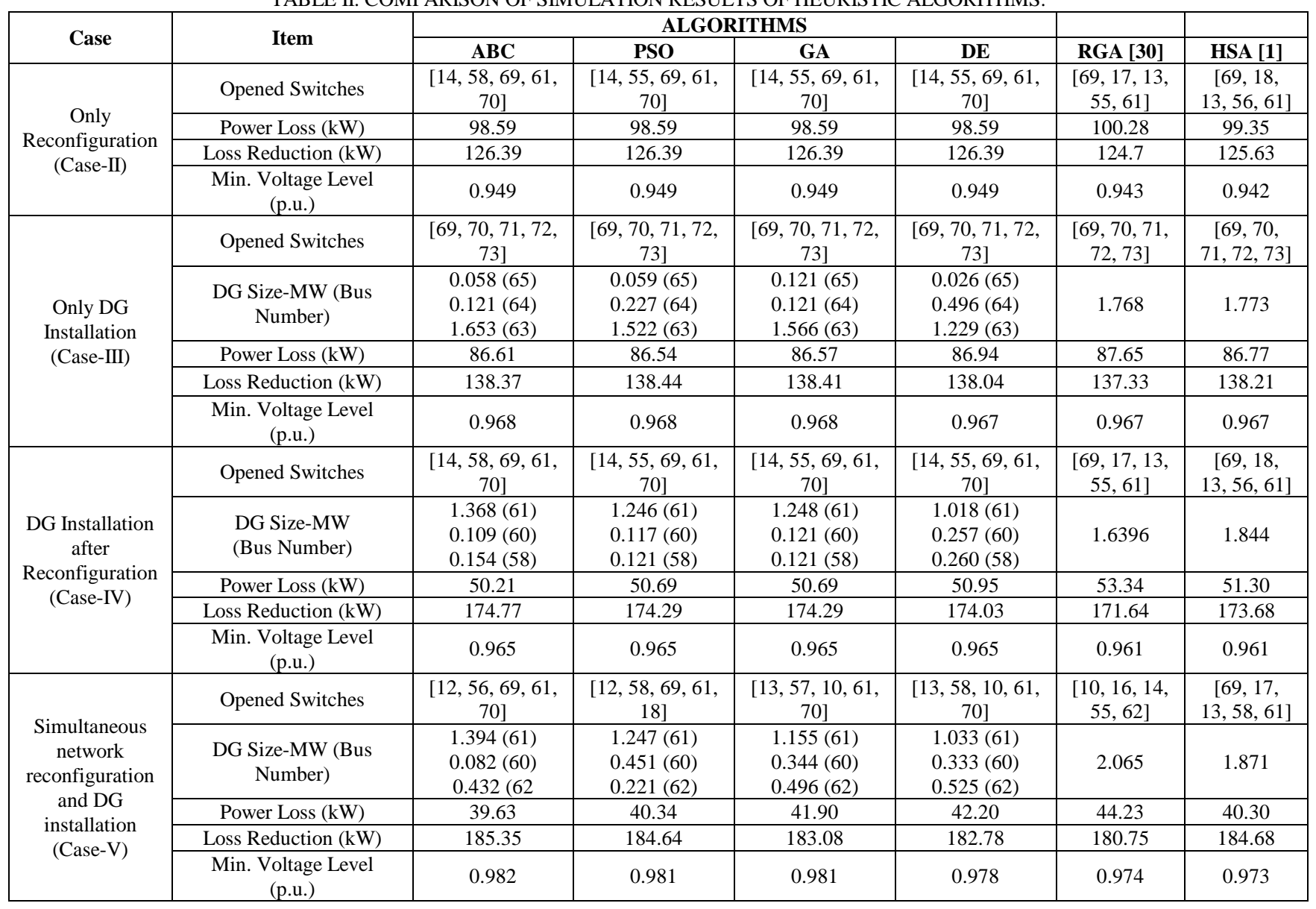


Locations of DGs are decided calculating loss sensitivity factors of each buses for Case III-IV-V. First three buses which have highest sensitivity are chosen for DG installation. The capacities of installed DGs and/or open switches are determined using given optimization algorithms for Case III-IV-V and results are given in Table II.

In Case-III, tie switches are open as in base case and only DG installation is provided. Bus 65, 64 and 63 are determined for DG installation based on loss sensitivity factor. Maximum loss reduction is provided by PSO with $138.44 \mathrm{~kW}$ and minimum loss reduction is presented by DE with $138.04 \mathrm{~kW}$. Minimum voltage level is 0.967 p.u. using DE while minimum voltage level is 0.968 p.u. using other optimization algorithms.

In Case-IV, DG installation is optimized after optimum system topology is decided. Open switches for optimum reconfigurations are same as in Case-II for each algorithm. Buses 58, 60 and 61 are determined for DG installation for each algorithm. Maximum loss reduction is provided by $\mathrm{ABC}$ with $174.77 \mathrm{~kW}$ and minimum loss reduction is presented by DE with $174.03 \mathrm{~kW}$. Minimum voltage levels of each given algorithm are calculated as 0.965 p.u.

In Case- $\mathrm{V}$, simultaneous network reconfiguration and DG installation are implemented to improve system efficiency. Bus 61, 60 and 62 are chosen for DG installation based on loss sensitivity factor. Total capacities of installed DG are 2.065 MW and 1.871 MW for RGA and HSA, respectively. Loss reduction is $185.35 \mathrm{~kW}, 184.64 \mathrm{~kW}, 183.08 \mathrm{~kW}$ and $182.78 \mathrm{~kW}, 180.75$ and 184.68 using ABC, PSO, GA, DE, RGA and HSA, respectively. Minimum voltage levels are 0.982 p.u., 0.981 p.u., 0.981 p.u., 0.978 p.u., 0.974 p.u. and 0.973 p.u. using ABC, PSO, GA, DE, RGA and HSA, respectively. In Case- $\mathrm{V}$, minimum power loss and maximum voltage level results are obtained in comparison to other cases. Also, ABC is the heuristic algorithm which ensures the minimum power loss and maximum voltage level in comparison to other given algorithms. HSA presents the second maximum loss reduction after ABC. RGA has the minimum lost reduction along the algorithms. Minimum voltage levels of HAS and RGA are lower than other simulated algorithms.

In Fig. 3, converge curve of the algorithms regarding to active power loss are given for Case- $\mathrm{V}$. ABC is the best algorithm reaching minimum losses with $39.63 \mathrm{~kW}$. PSO is the second algorithm with $40.34 \mathrm{~kW}$ although it has worst initialization with $73.4 \mathrm{~kW}$. PSO also reaches optimum value before 20th iteration. In the end of 100 iterations, power losses of GA and DE are $41.90 \mathrm{~kW}$ and $42.20 \mathrm{~kW}$, respectively.

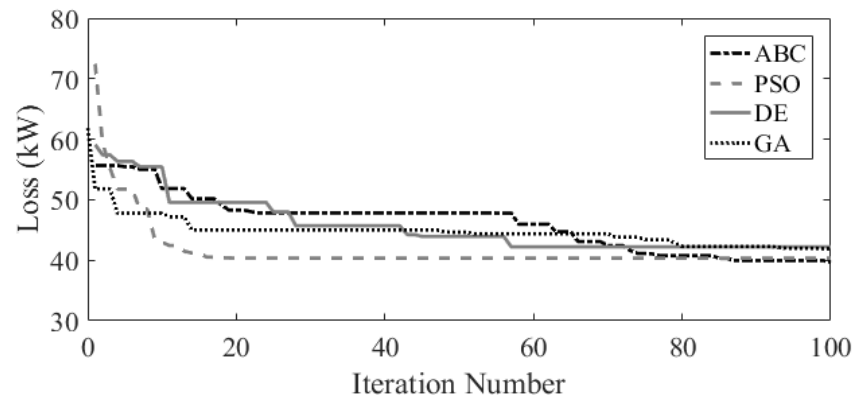

Fig. 3. Convergence curve of algorithms for Case-V.
In Fig. 4, comparisons of voltage level of each bus are given for Case-V. Voltage level of each bus is varied based on opened switched and size of installed DG. The shapes of voltage profile of the algorithms are similar except changes in voltage magnitude.

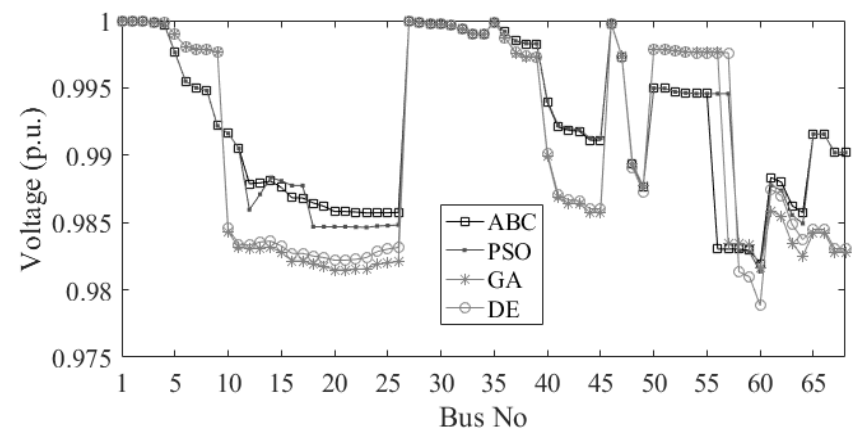

Fig. 4. Voltage profile comparison of simulated algorithm for Case-V.

In Fig. 5, voltage levels of each bus are compared with other cases optimized by ABC. As seen, simultaneous network reconfiguration and DG installation (Case-V) provides most efficient solution on system improvement in comparison to other cases.

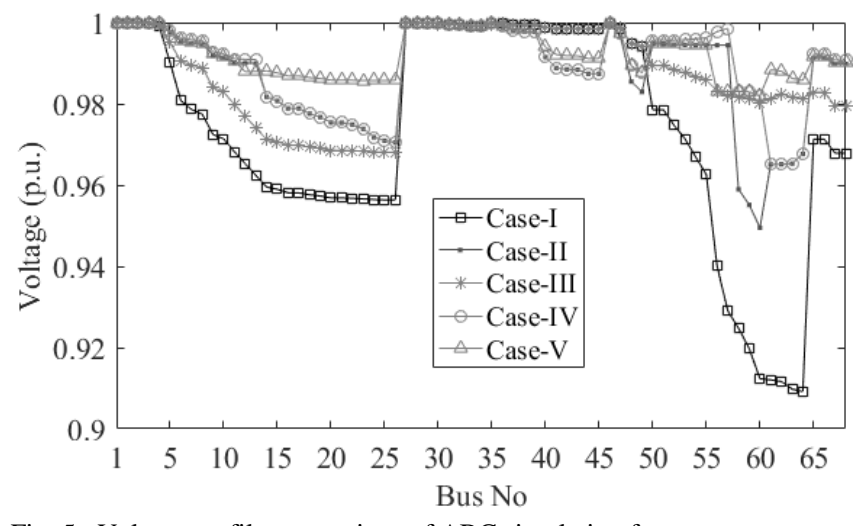

Fig. 5. Voltage profile comparison of ABC simulation for cases.

\section{DISCUSSION}

Efficiency of 69 bus system is improved with different scenarios of network reconfiguration and DG installation in this study. Average voltage is 0.9734 p.u. for 69 bus system. Heuristic algorithms are used in order to provide optimum operation in each case. Average voltages are 0.9877 p.u., 0,9872 p.u., 0,9895 p.u. and 0.9923 p.u. for Case-II, CaseIII, Case-IV and Case-V using ABC, respectively. Simultaneous network reconfiguration and DG installation (Case-V) provides best system performance among the other cases. Minimum voltage level does not decrease lower than 0.973 p.u. with any of the simulated algorithms in Case-V. Minimum voltage level and loss reduction are 0.982 p.u. and $185.35 \mathrm{~kW}$ with $\mathrm{ABC}$ which presents the best results for Case-V. PSO has the worst initial value for Case-V as shown in Fig. 3. However, PSO reached the optimum value in least number of iteration. Initial values are $55.65 \mathrm{~kW}, 72.47 \mathrm{~kW}$, $59.10 \mathrm{~kW}$ and $62.08 \mathrm{~kW}$ using ABC, PSO, DE and GA. Final loss values are $39.63 \mathrm{~kW}, 40.34 \mathrm{~kW}, 41.90 \mathrm{~kW}$, $42.20 \mathrm{~kW}, 44.23 \mathrm{~kW}$ and $40.30 \mathrm{~kW}$ using ABC, PSO, DE, GA, RGA and HAS, respectively.

Most loss reduction is provided by ABC for Case-IV with $174.77 \mathrm{~kW}$. In Case-III, minimum voltage levels of the 
algorithms are almost same but most loss reduction is provided by PSO with $138.44 \mathrm{~kW}$. In Case-II, simulated algorithms provide same loss reduction and minimum voltage level.

\section{CONCLUSIONS}

In this paper, network reconfiguration and DG installation is solved separately and simultaneously using most popular heuristic algorithms such as ABC, DE, PSO and GA. Results are also compared with HAS and RGA which are exist in the literature. Loss sensitivity factor of each buses are calculated and buses which have highest sensitivity are chosen for DG placement. Simulation results demonstrate that simultaneous network reconfiguration and DG installation (Case-V) presents minimum active power losses and maximum voltage level in comparison of other cases which the problems are solved separately. Each of given algorithm provides same loss rates for only network reconfiguration (Case-II). PSO presents the minimum power loss for only DG installation (Case-III). HSA presents satisfactory solution for simultaneous network reconfiguration and DG installation (Case-V). However, ABC is the best algorithm for DG installation after reconfiguration (Case-IV) and (Case-V).

\section{REFERENCES}

[1] R. S. Rao, K. Ravindra, K. Satish, S. V. L. Narasimham, "Power loss minimization distribution system using network reconfiguration in the presence of distributed generation", IEEE Trans. Power Syst., vol. 28, pp. 317-325, 2013. DOI: 10.1109/TPWRS.2012.2197227.

[2] M. E. Baran, F. F. Wu, "Network reconfiguration in distribution systems for loss reduction and load balancing", IEEE Trans. Power Del., vol. 4, pp. 1401-1407, 1989. DOI: 10.1109/61.25627.

[3] C. T. Su, C. F. Chang, J. P. Chiou, "Distribution network reconfiguration for loss reduction by ant colony search algorithm", Electr. Power Syst. Res., vol. 75, pp. 190-199, 2005. DOI: 10.1016/j.epsr.2005.03.002.

[4] Y. J. Jeon., J. C. Kim., J. O. Kim, J. R. Shin, K.Y. Lee, “An efficient simulated annealing algorithm for network reconfiguration in largescale distribution systems", IEEE Trans. Power Deliv., vol. 17, pp. 1070-1078, 2002. DOI: 10.1109/TPWRD.2002.803823.

[5] E. M. Carreno, R. Romero, A. Padilha-Feltrin, "An efficient codification to solve distribution network reconfiguration for loss reduction problem", IEEE Trans. Power Syst., vol. 23, pp. 1542 1551, 2008. DOI: 10.1109/TPWRS.2008.2002178.

[6] A. Y. Abdelaziz, F. M. Mohamed, S. F. Mekhamer, M. A. L. Badr, "Distribution system reconfiguration using a modified Tabu Search algorithm", Electr. Power Syst. Res., vol. 80, pp. 943-953, 2010. DOI: 10.1016/j.epsr.2010.01.001

[7] A. Y. Abdelaziz, F. M. Mohamed, S. F. Mekhamer, M. A. L. Badr, "Distribution systems reconfiguration using a modified particle swarm optimization algorithm", Electr. Power Syst. Res., vol. 79, pp. 1521-1530, 2009. DOI: 10.1016/j.epsr.2009.05.004.

[8] C. Wang, H. Z. Cheng, "Optimization of network configuration in large distribution systems using plant growth simulation algorithm", IEEE Trans. Power Syst., vol. 23, pp. 119-126, 2008. DOI 10.1109/TPWRS.2007.913293.

[9] A. M. Imran, M. Kowsalya, "A new power system reconfiguration scheme for power loss minimization and voltage profile enhancement using fire works algorithm", Int. J. Electr. Power Energy Syst., vol. 62, pp. 312-322, 2014. DOI: 10.1016/j.ijepes.2014.04.034.

[10] C. Lee, C. Liu, S. Mehrotra, Z. Bie, "Robust distribution network reconfiguration", IEEE Trans. on smart grid., vol. 6, pp. 837-842, 2015. DOI: 10.1109/TSG.2014.2375160.

[11] T. N. Shukla, S. P. Singh, V. Shrinivasarao, K. B. Naik, "Optimal sizing of distributed generation placed on radial distribution systems", Elect. Power Compon. Syst., vol. 38, pp. 260-274, 2010. DOI: $10.1080 / 15325000903273403$.
[12] R. S. Al Abri, E. F. El-Saadany, Y. M. Atwa, "Optimal placement and sizing method to improve the voltage stability margin in a distribution system using distributed generation", IEEE Trans. Power Syst., vol. 28, pp. 326-334, 2013. DOI: 10.1109/TPWRS.2012.2200049.

[13] D. Q. Hung, N. Mithulananthan, "Multiple distributed generators placement in primary distribution networks for loss reduction", IEEE Trans. Ind. Electron., vol. 60, pp. 1700-1708, 2013. DOI: 10.1109/TIE.2011.2112316.

[14] S. Kansal, K. Vishal, T. Barjeev, "Optimal placement of different type of DG sources in distribution networks", Int. J. Electr. Power Eng. Syst., vol. 53, pp. 752-760, 2013. DOI: 10.1016/j.ijepes.2013.05.040.

[15] S. Bahceci, A. Dogan, T. Yalcinoz, F. Daldaban, "Energy storage system location selection for smart grid applications on distribution networks", Electrical Engineering, vol. 99, pp. 357-366, 2017. DOI 10.1007/s00202-016-0416-z.

[16] A. Ameli, S. Bahrami, F. Khazaeli, M. R. Haghifam, "A multiobjective particle swarm optimization for sizing and placement of DGs from DG owner's and distribution company's viewpoints", IEEE Trans. Power Deliv., vol. 29, pp. 1831-1840, 2014. DOI: 10.1109/TPWRD.2014.2300845.

[17] N. M. Ranjan, "Optimal feeder reconfiguration of distributed system with distributed generation units using Hypercube-Ant Colony optimization algorithm", Int. J. Electr. Eng. Inform., vol. 6, pp. $107-$ 128, 2014. DOI: 10.15676/ijeei.2014.6.1.8

[18] R. Rajaram, K. S. Kumar, N. Rajasekar, "Power system reconfiguration in a radial distribution network for reducing losses and to improve voltage profile using modified plant growth simulation algorithm with Distributed Generation (DG)", Energy Reports, vol. 1, pp. 116-122, 2015. DOI: 10.1016/j.egyr.2015.03.002.

[19] W. M. Dahalan, H. Mokhlis, R. Ahmad, A. H. Abu Bakar, I. Musirin, "Simultaneous network reconfiguration and DG sizing using evolutionary programming and genetic algorithm to minimize power losses", Arabian J Sci. Eng., vol. 39, pp. 6327-6338, 2014. DOI: 10.1007/s13369-014-1299-9

[20] D. Das, D. P. Kothari, A. Kalam, "Simple and efficient method for load flow solution of radial distribution networks", Int. J. Elect. Power Energy Syst. Eng., vol. 17, no. 5, pp. 335-346, 1995. DOI: 10.1016/0142-0615(95)00050-0.

[21] A. Dogan, S. Bahceci, F. Daldaban, M. Alci, "Optimization of charge/discharge coordination to satisfy network requirements using heuristic algorithms in vehicle-to-grid concept", Advances in Electrical and Computer Engineering, vol. 18, no. 1, pp. 121-130, 2018. DOI: 10.4316/AECE.2018.01015.

[22] J. H. Holland, Adaptation in Natural and Artificial Systems: An Introductory Analysis with Applications to Biology, Control and Artificial Intelligence. Cambridge, MA: MIT Press. Second edition, 1992. DOI: 10.7551/mitpress/1090.001.0001.

[23] K. V. Price, "Differential evolution: a fast and simple numerical optimizer", Fuzzy Inf. Proc. Soc. Bienn. Conf. (NAFIPS 1996), 1996, pp. 524-527. DOI: 10.1109/NAFIPS.1996.534790.

[24] J. Kennedy, R. Eberhart, "Particle swarm optimization", in Proc. IEEE Int. Conf Neural Networks, vol. 4, 1995, pp. 1942-1948.

[25] D. Karaboga, "An idea based on honey bee swarm for numerical optimization", Technical Report TR06, Erciyes University, Eng. Faculty, Computer Engineering Department, 2005.

[26] T. Koza, N. Karaboga, S. Kockanat, "Aort valve doppler signal noise elimination using IIR filter designed with ABC algorithm", Int. Symposium on Innovations in Intelligent SysTems and Applications (INISTA 2012), 2012, pp. 1-5. DOI: 10.1109/INISTA.2012.6247038.

[27] A. R. Abbasi, A. R. Seifi, "Considering cost and reliability in electrical and thermal distribution networks reinforcement planning", Energy, vol. 84, pp. 25-35, 2015. DOI: 10.1016/j.energy.2015. 01.113 .

[28] J. S. Savier, D. Das, "Impact of network reconfiguration on loss allocation of radial distribution systems", IEEE Trans. Power Del., vol. 2, pp. 2473-2480, 2007. DOI: 10.1109/TPWRD.2007.905370

[29] A. Dogan, T. Yalcinoz, M. Alci, "A comparison of heuristic methods for optimum power flow considering valve point effect", Elektronika Ir Elektrotechnika, vol. 22, pp. 32-37, 2016. DOI: 10.5755/j01.eie.22.5.16340.

[30] J. Z. Zhu, "Optimal reconfiguration of electrical distribution network using the refined genetic algorithm", Elect. Power Syst. Res., vol. 62, pp. 37-42, 2002. DOI: 10.1016/S0378-7796(02)00041-X. 